\title{
PARTISIPASI IBU-IBU JAMAAH PENGAJIAN YASINAN DALAM MENINGKATKAN KEPEDULIAN SOSIAL MASYARAKAT
}

\author{
Ratna Dwi Mei Wulandari \\ Sulistyo Anjarwati \\ Email: Ratnamay9@gmail.com \\ Universitas Islam Balitar
}

\begin{abstract}
Community life has never been separated from social care. Social care is an interest or interest in helping others. The closest environment has a big influence in determining the level of social awareness. To increase the social sense, it can be through various activities, both religious activities and other activities. In this study the researchers focused more on religious activities, namely the activities of recitation of Yasinan. This research was conducted in Sumberjo Village, Sutojayan Sub-District, Blitar District. Data collection is done by interviews, documentation and observations in these activities. The results of the study indicate that the Yasinan Recitation Committee has activity agendas, ranging from the annual agenda to the agenda to be implemented. This activity is carried out on the basis of Islamic brotherhood which they believe can be intimately carried out by carrying out routine and structured religious activities and for the pilgrims to recite this sense of caring that is considered very important in carrying out Islamic teachings and fostering a sense of social care.
\end{abstract}

Keywords: Participation, Religious Activities, Social Concern

ABSTRAK

Kehidupan bermasyarakat tidak pernah terlepas dari kepedulian sosial. Kepedulian social adalah minat atau ketertarikan untuk membantu orang lain. Lingkungan terdekat berpengaruh besar dalam menentukan tingkat kepedulian social. Untuk meningkatkan rasa social bisa melalui berbagai kegiatan, baik kegiatan keagamaan maupun kegiatan-kegiatan lainnya.Dalam penelitian ini peneliti lebih terfokus pada kegiatan keagamaan yaitu kegiatan pengajian Yasinan. Penelitian ini dilakukan di Desa Sumberjo Kecamatan Sutojayan Kabupaten Blitar. Pengumpulan data dilakukan dengan wawancara, dokumentasi juga observasi dalam kegiatan tersebut. Hasil penelitian menunjukkan bahwa Jamaah pengajian yasinan memiliki agenda-agenda kegiatan, mulai dari agenda tahunan hingga agenda yang akan dilaksanakan. Kegiatan ini dilakukan atas dasar ukhuwah islamiyah yang mereka yakini bisa terjalini dengan erat dengan dilakukannya kegiatan keagamaan secara rutin dan terstruktur dan bagi ibu-ibu jamaah pengajian yasinan rasa kepedulian ini dianggap sangat penting dalam rangka menjalankan ajaran islam dan menumbuhkan rasa kepedulian social.

KataKunci: Partisipasi, Kegiatan Religius, Kepedulian Social. 


\section{PENDAHULUAN}

Setiap masyarakat memiliki peranan penting dalam kehidupannya. Interaksi social menjadi keharusan yang selalu dilakukan dalam kehidupan sebagai masyarakat social. Interaksi social merupakan media bagi masyarakat untuk saling mengenal, mengetahui dan memahami masyarakat lainnya.Tentu tujuannya adalah untuk melakukan komunikasi social yang saling memberikan kemanfaatan.

Kehidupan social masyarakat bergerak sesuai zamannya.Kondisi saat ini menunjukkan bahwa social kemasyarakatan sudah bergeser acuh tak acuh kepada tetangganya, lebih mementingkan kehidupan pribadinya, hanya sedikit yang mempunyai rasa kasih dan simpati kepada orang lain, seiring dengan kehidupan yang penuh kesenangan dan mempunyai tujuan hidupnya sendiri.

Oleh karena itu, dibutuhkan sebuah penyegaran dan penguatan bagi masyarakat dalam mengenali diri sendiri dan masyarakatnya.Pengajian Yasinan merupakan bagian yang sudah lama menjadi tradisi bagi masyarakat.Kegiatan pengajian Yasinan hendaknya terus dikembangkan dan dijadikan sebagai rutinitas. Dimana tidak hanya membaca surat yasin dan tahlil sertakajian ilmu agama saja tetapi dapat diberikan tambahan untuk bertanya jawab juga melakukan kegiatan sosial untuk menumbuhkan kepedulian sosial.

Rumusan permasalahan penelitian ini adalah Bagaimana pelaksanaan kegiatan Jamaah Pengajian Yasinan di Desa Sumberjo RT. 03 RW. 02? Bagaimana partisipasi ibu-ibu jamaah pengajian yasinan dalam menumbuhkan kepedulian sosial masyarakat? Kegiatan social apa saja yang bisa meningkatkan kepedulian masyarakat?

Tujuan penelitian adalah untuk mengetahui dan mendeskripsikan partisipasi ibu-ibu jamaah pengajian yasinan dalam meningkatkan kepedulian social masyarakat di Desa Sumberjo RT. 03 RW. 02. Untuk mengetahui dan mendeskripsikan kegiatan social apa saja yang bisa meningkatkan kepedulian social masyarakat di Desa Sumberjo RT. 03 RW. 02.

Kepedulian social dapat diartikan sebagai wujud rasa peduli terhadap kepentingan umum. Kepedulian social merupakan salah satu bentuk proses social yang diartikan sebagai pengaruh timbal balik antara berbagai segi kehidupan (Huda \& Martanti, 2018). Sehingga diharapkan dalam masyarakat tidak akan terjadi sikap saling membedakan namun justru sebaliknya yaitu sikap saling tanggap dan saling peduli terhadap sesama.

\section{METODE PENELITIAN}

Penelitian ini dialkukan dengan menggunakan jenis kualitatif yang dilakukan dengan menggunakan data subyek yang artinya informan atau fakta yang didapatkan didinterprestasikan oleh peneliti dengan mengacu pada konsep atau teori, kemudian disimpulkan dan dipahami secara holistic, 
sistematis..pendekatan yang digunakan oleh peneliti adalah Edmund Husserl (1859-1939) yang dikutip oleh (Romdon, 1996:84), ia menyatakan bahwa manusia dapat menangkap realitas dengan cara yang alami, spontan, dengan bermacam-macam cara penggunaan indera dari melihat, mendengar, meraba, dan menangkap dunia.Penelitian ini dilakukan di Desa Sumberjo Kecamatan Sutojayan Kabupaten Blitar.Tepatnya pada jamaah pengajian Yasinan yang terletak di Desa Sumberjo RT. 03 RW. 02.Waktu penelitian dilakukan tanggal 3 November - 22 November 2017.Subyek penelitian ini adalah ketua jamaah pengajian yasinan dan ibu-ibu jamaah pengajian Yasinan Desa Sumberjo RT. 03 RW. 02.Penelitian ini menggunakan observasi, dokumentasi dan wawancara mendalam.

\section{HASIL DAN PEMBAHASAN}

\section{Sejarah Berdirinya Jamaah Pengajian Yasinan di Desa Sumberjo}

Jamaah pengajian Yasinan di desa Sumberjo merupakan pendidikan nonformal yang berdiri sejak tahun 1974 yang didirikan oleh Bapak Afandi.Pada awal berdirinya, kegiatan tersebut hanya terdapat 1 jamaah pengajian Yasinan dalam satu desa dan bertempat di Madin Sumberjo Timur.Jumlah anggotanya pun masih sedikit, kurang lebih 15-20 orang paling banyak. Setelah tahun 1974 kirakira tahun 1978 pengajian Yasinan mulai berkembang, yang mulanya satu desa hanya terdapat di 1 tempat lalu bertambah menjadi 2 tempat. Sekitar tahun 1990 pengajian Yasinan mengalami perkembangan lagi menjadi 3 tempat dalam 1 desa, pada tahun ini ada semacam tamu dari desa lain yang mengisi pengajian Yasinan di Desa Sumberjo dengan ceramah yang kurang lebih berjalan sekitar 2 tahun. Pengisi ceramah tadi bernama Ibu Kiromahdan Bapak Sofyan yang mengisi tiap 1 bulan sekali. Penjelasan di atas sesuai dengan penjelasan Ibu $\mathrm{Hj}$. Hanik selaku Ketua Jamaah Pengajian Yasinan desa Sumberjo RT. 03 RW. 02:

Pada awal berdirinya tahun 1974 di desa hanya ada 1 tempat Yasinan yaitu di Madin Sumberjo Timur.Tiap minggu diadakan satu kali, pengikutnya juga hanya sedikit tidak lebih dari 20 orang. Setelah itu kira-kira tahun 19781 desa ada 2 tempat, lalu berkembang lagi pada tahun 1990 menjadi 3 tempat. Pada tahun ini ada tamu dari desa lain untuk ceramah atau mengisi pengajian yasinan selama kurang lebih 2 tahun, namanya Ibu Kiromah dan Bapak Sofyan yang mengisi sebulan sekali. (Wawancara, 11 November 2017)

Kegiatan ini seiring berjalannya waktu, sekitar pada tahun 1993 dalam 1 desa sudah terdapat 5 tempat pengajian Yasinan yang berjalan sampai tahun 2000. Setelah perkembangannya di tahun 2000 pengajian Yasinan mengalami perkembangan yang cukup baik yaitu tiap RT. mengadakan pengajian Yasinan rutinan yang diadakan tiap satu minggu sekali dan jumlah jamaahnya pun kurang lebih tiap RT. ada 50 orang. Selain pengajian Yasinan yang rutin diadaka setiap 
satu minggu sekali juga ada banyak kegiatan keagamaan yang dilakukan di desa Sumberjo seperti rutinan Yasinan Muslimat se kecamatan tiap 2 tahun sekali, Khotmil Qur'an se kecamatan, manakib, dibaan, dan berjanji.

\section{Visi, Misi dan Tujuan Jamaah Pengajian Yasinan di Desa Sumberjo}

Layaknya sebuah lembaga atau organisasi lainnya, Jamaah Pengajian Yasinan di Desa Sumberjo RT. 03 RW. 02 tentunya memiliki visi, misi dan tujuan yang merupakan patokan utama untuk acuan dalam melaksanakan kegiatannya. Adapun visi, misi dan tujun tersebut adalah sebagai berikut:

a. Visi

Mewujudkan generasi Islam yang beriman dan bertaqwa serta berbudi luhur (aqlaq al-karimah) berguna bagi agama dan masyarakat sesuai petunjuk alQur'an dan hadits.

b. Misi

1. Mengedepankan rasa persatuan dan persaudaraan sesama umat Islam.

2. Menumbuhkan rasa cinta, syukur dan ikhlas serta tawakal kepada Allah Swt dan mengharap keridhoanNya.

3. Menumbuhkan kecintaan kepada Rasulullah Muhammad SAW. dengan menjalankan sunnahnya guna memperoleh syafaatnya di yaumil akhir.

c. Tujuan

1. Untuk mendekatkan diri kepada Allah SWT

2. Untuk lebih mempererat ukhuwah Islamiyah dan kebersamaan

Tujuan ini sesuai dengan pendapat Amin (1997:16) dalam bukunya yang sudah dibahas di tinjau pustaka yaitu, untuk masyarakat yaitu terbentuknya masyarakat sejahtera yang penuh dengan suasana keislaman. Suatu masyarakat dimana anggota-anggota mematuhi peraturan-peraturan yang telah disyariatkan oleh Allah swt, baik yang berkaitan antara hubungan manusia dengan tuhannya, manusia dengan sesamanya, maupun manusia dengan alam sekitarnya, saling bantu-membantu, penuh rasa persaudaraan, persamaan dan sebasib sepenanggungan.

\section{Struktur Kepengurusan Jamaah Pengajian Yasinan di Desa Sumberjo}

Susunan kepengurusan jamaah pengajian yasinan di desa Sumberjo RT. 03 RW. 02 mulai disusun setelah tahun 2000. Berikut susunan kepengurusan pada tahun 2014:

$\begin{array}{ll}\text { Ketua } & : \text { Hj. Umi Hanik } \\ \text { Penasehat } & : \text { Mariyanah } \\ \text { Sekretaris } & : \text { Nur Baidah } \\ \text { Bendahara } & : \text { Alminatun }\end{array}$




\section{Pelaksanaan Kegiatan Jamaah Pengajian Yasinan di Desa Sumberjo}

Pelaksanaan kegiatan jamaah pengajian yasinan dimulai seusai shalat maghribpada hari Rabu malam Kamis. Adapun metodenya adalah dengan silaturrahmi keliling dari rumah ke rumah jamaah lainnya yang berjumlah 42 orang.Diharapkan dengan metode ini, silaturahmi antar jamaah dapat senantiasa terjaga.

Setelah semua anggota jamaah yasinan berkumpul kemudian dibuka oleh Ustadz setempat yang sudah dijadwalkan untuk sekedar memberikan ceramah atau materi.Materi tersebut bisa berkaitan dengan sejarah Nabi, fiqih, mu'amalah, terjemah ayat dan do'a-do'a sesuai dengan kemampuan ustadz yang membimbing. Adapun setelah ceramah selesai dilanjut oleh kegiatan yasinan yang dipimpin oleh anggota jamaah yang sudah dijadwalkan untuk memulai kegiatan dengan membaca surat al-Fatihah terlebih dahulu kemudian dilanjutkan Istighfar, kemudian pembacaan Surah Yasin dan Tahlil.

Kegiatan selanjutnya yaitu komplongan atau infaq. Infaq dilakukan dengan cara megedarkan tas infaq kesetiap anggota jamaah yasinan yang kurang lebih membutuhkan waktu 10 menit. Ketika proses infaq berlangsung bendahara jamaah pengajian yasinan seketika itu juga memanggil setiap anggota untuk membayar uang arisan. Bila infaq dilakukan secara sukarela, maka arisan disini bersifat wajib dengan membayar Rp. 5000,-.Arisan dan Infaq digunakan untuk hal yang berbeda, arisan digunakan untuk meringankan beban anggota jamaah yasinan yang kebetulan akan mendapat gilir pada minggu berikutnya, sedangkan infaq untuk menambah dana jamaah pengajian yasinan juga untuk kegiatankegiatan seperti santunan anak yatim dan warga kurang mampu.

\section{Kegiatan-Kegiatan pada Jamaah Pengajian Yasinan di Desa Sumberjo}

Kegiatan Jamaah Pengajian Yasinan di Desa Sumberjo RT. 03 RW. 02 memiliki berbagai agenda.Baik agenda tahunan yang berupa pengajian umum menjelang bulan puasa, mengaji gilir pada saat Nuzulul Qur'an di masjid, dan pengajian di musholla dengan mengundang da'I pada acara Safari Romadhon. Sedangkan agenda yang akan segera dilakukan yaitu melakukan ziarah wali dan kunjungan ke tempat wisata religi.

Agenda lainnya berupa kegiatan social yaitu menjenguk anggota Jamaah Pengajian Yasinan yang sakit, jamaah yasinan yang melahirkan, takziah, sambang rekan yang melaksanakan umrah dan haji serta santunan terhadap anak yatim dan kaum dhuafa.

Hal ini sesuai dengan pendapat (Antonius, 2002:263) Hidup di dunia ini diciptakan dua jalan. Pertama, hidup dengan senang tetapi tidak banyak bernilai.Yang kedua, hidup suah tetapi bernilai. Jalan hidup susah mendaki lagi sukar itulah sebenarnya jalan yang harus ditempuh oleh manusia, itulah jalan yang 
benar, itulah jalan yang bernilai. Tetapi sedikit orang yang mau menempuh jalan itu. Jalan itu penuh pengorbanan .yaitu jalan yang penuh pengabdian social. Jalan yang penuh makna kepedulian social bagi sesama yang susah dan penuh penderitaan.

Bukan sekedar agenda intern saja namun jamaah yasinan di Desa Sumberjo juga melakukan interaksi dengan jamaah yasinan di luar desa. Hal ini terbukti dengan keikutsertaan Jamaah Pengajian Yasinan Desa Sumberjo mengikuti kegiatan rutinan Yasin Muslimat se Kecamatan Sutojayan 2 tahun sekali, juga mengikuti kegiatan Khotmil Qur'an se Kecamatan Sutojayan.

Pernyataan di atas di ungkapkan oleh ketua Jamaah Pengajian Yasinan Desa Sumberjo T.t 03 RW. 02 yakni Ibu Hj. Hanik :

Jamaah yasinan Sumberjo memiliki agenda tahunan yang berupa mengadakan pengajian umum menjelang bulan puasa, mengaji gilir pada saat Nuzulul Qur'an di masjid, dan pengajian di musholla dengan mengundang da'I pada acara Safari Romadhon. Namun hal tersebut dilakukan tetap dengan musyawarah dengan para anggota jamaah pengajian yasinan. Sedangkan agenda yang akan dilaksanakan yaitu melakukan ziarah wali dan kunjungan ke tempat wisata religi. Selain agenda tersebut banyak kegiatan sosial yang dilakukan oleh jamaah pengajian yasinan desa Sumberjo yaitu menjenguk anggota jamaah yasinan yang sakit, jamaah yasinan yang melahirkan, takziah, sambaing rekan pulang umrah dan haji serta santunan anak yatim dan kaum dhuafa. Bukan sekedar agenda intern saja, tapi jamaah yasinan desa Sumberjo juga melakukan interaksi dengan jamaah yasinan luar desa, yaitu mengikuti kegiatan rutinan Yasinan Muslimat se Kecamatan Sutojayan 2 tahun sekali dan juga mengikuti kegiatan Khotmil Qur'an.(Wawancara, 11 November 2017

\section{Nilai-Nilai Kepedulian Sosial pada Kegiatan Jamaah Pengajian Yasinan desa Sumberjo RT. 03 RW. 02}

Nilai-nilai kepedulian social pada kegiatan Jamaah Yasinan desa Sumberjo RT. 03 RW. 02 ditunjukkan melalui kegiatan infaq yang dilakukan setiap hari Rabu malam Kamis yang disalurkan untuk kegiatan santunan anak yatim, kaum dhuafa maupun anggota jamaah yasinan yang tertimpa musibah seperti sakit, atau meninggal.

Dari agenda social ini Jamaah Yasinan desa Sumberjo RT. 03 RW. 02 memiliki harapan besar untuk senantiasa melatih rasa ikhlas dalam meringankan beban sesame. Hal ini di ungkapkan oleh Ibu Winarti selaku anggota jamaah yasinan desa Sumberjo :

Infaq merupakan salah satu cara kita agar hidup lebih berkah. Untuk sedikit meringankan beban sesame yang manfaatnya bisa membawa kebahagiaan lahir dan batin walaupun sebenarnya infaq hanya secuil dari apa yang kita miliki. Untuk itu kegiatan yang sudah baik ini saya harap 
senantiasa dapat mengajari kita untuk senantiasa bersyukur. (Wawancara, 13 November 2017)

Sedangkan menurut Eli sebagai anak yatim yang saat ini masih duduk dibangku kelas 3 di MI Al-Ma'arif Margomulyo 01 yang juga menerima santunan mengungkapkan bahwa santunan yang diadakan Jamaah Yasinan sangat membuatnya senang sebab bisa membantu membeli alat tulis dan sisanya untuk ditabung. Berikut kutipannya:

Saya merasa sangat senang atas bantuan ini, karena lumayan bisa untuk membeli buku tulis dan bolpoin yang sisanya untu di tabung.Kegiatan ini bermanfaat sekali.(Wawancara, 13 November 2017)

\section{MEMBANGUN PARTISIPASI IBU-IBU JAMAAH PENGAJIAN YASINAN DI DESA SUMBERJO}

Ibu-ibu pengajian yasinan tentunya memiliki pengaruh yang besar bagi keberlangsungan kegiatan pengajian yasinan. Mulai dari cara ibu-ibu pengajian yasinan aktif mengajak warga untuk mengikuti kegiatan pengajian yasinan juga partisipasi ibu-ibu pengajian yasinan dalam menjaga kekompakan antar anggota jamaah yasinan, yaitu: 1) Ketua harus mengamati para anggota, maksutnya harus mengerti seluk beluk anggota dan tidak mempunyai pendapat sendiri/diadakan musyawarah bersama, 2) Bila ada permasalahan maka dibicaran bersama dan dicari solusinya, 3) Bila ingin mengambil keputusan harus mendengar pendapat dari semua pihak lalu di ambil yang positif. Kegiatan ini merupakan bagaian dari eksistensi perempuan dalam berorganisasi (Frenti \& Huda, 2018), sehinga perempuan tidak lagi hanya sebagai orang kedua atau selaku pekerja rumah tangga saja (Huda, 2016).

Selain menjaga kekompakan ibu-ibu yasinan juga mencari dana untuk keberlangsungan kegiatan pengajian yasinan, yaitu dengan cara sebagai berikut: 1) Setiap musim panen diadakan jimpitan (iuran) yang masuk kas untuk kepentingan jamaah sejumlah seikhlasnya, 2) Tisap satu minggu sekali diadakan komplongan (infaq) untuk kepentingan jamaah, 3) Sedikit dari uang hasil arisan diambil $10 \%$ untuk kas.

Menurut ibu-ibu pengajian yasinan pengajian yasinan tidak bisa dibubarkan dikarenakan pengajian yasinan telah menjadi rutinitas dan para anggotanya sudah seperti keluarga dan pengajian yasinan merupakan kegiatan yang sangat penting juga berguna bagi warga untuk menumbuhkan kepedulian social. Hal ini sesuai dengan pendapat Ibu $\mathrm{Hj}$. Hanik ketika ditanya Bagaimana jika pengajian yasinan dibubarkan?. Beliau menjawab:

Tidak bisa, karena pengajian yasinan sudah menjadi rutinitas dan para anggotanya sudah seperti keluarga.Selain itu pengajian yasinan juga sangat penting dan berguna bagi warga untuk menumbuhkan kepedulian social. (Wawancara, 11 November 2017) 
Dalam kegiatannya tentunya kegiatan pengajian yasinan tidak berjalan secara mulus, ada juga masalah yang harus dihadapi oleh ibu-ibu jamaah pengajian yasinan, seperti: 1) Beda pendapat antar anggota, jika terjadi masalah seperti ini maka solusinya dipecahkan secara bersama atau musyawarah, 2) Kesulitan mencarai dana, solusinya ibu-ibu pengajian yasinan mengumpulkan dana dari anggota atau yang di sebut komplongan yang kemudian akan dimasukkan kas, 3) Kadang yang mengisi materi atau ceramah tidak cocok yang akhirnya para jamaah menggerutu dan tidak mendengarkan ceramah, maka solusinya melakukan rembukan atau musyawarah yang kemudian baru diberitahukan kepada ustadz yang mengisi tadi agar ceramah atau mengisi materinya tidak panjang-panjang agar jamaah tidak jenuh, 4) Sulit mengajak para remaja atau ibu-ibu lain untuk ikut kegiatan pengajian yasinan, solusi yang dilakukan yaitu mengadakan anjangsana dan giat mengajak para remaja dan ibuibu lain untuk ikut kegiatan yasinan.

\section{MENINGKATKAN NILAI KEPEDULIAN SOSIAL MASYARAKAT}

Kodrat manusia yang diciptakan Allah sebagai makhluk individu sekaligus makhluk social yang mana sebagai makhluk individu selalu membutuhkan interaksi dengan orang lain maka sebagai manusia tidak akan pernah lepas dari hubungan social.

Memang sudah seharusnya sebagai manusia wajib berinteraksi dalam social masyarakat. Untuk itu tidak akan pernah lepas dengan perasaan social mengaitkan individu dengan seama manusia yaitu perasaan untuk hidup bermasyarakat dengan sesame manusia, untuk bergaul, saling tolong menolong serta menerima dan memberi.

Kegiatan infaq pada kegiatan Jamaah Yasinan desa Sumberjo sebagai wadah pelatihan bagi anggota jamaahnya untuk selalu belajar bersosialisasi dengan orang lain di sekelilingnya, memiliki jiwa kepedulian yang tinggi terhadap sesama terutama kepada orang-orang yang membutuhkan bantuan. Bagaimanapun sebagai makhluk, manusia tidak akan pernah bisa hidup tanpa orang lain. Oleh karena itu pembiasaan infaq yang dilakukan oleh ibu-ibu jamaah yasinan penting untuk selalu dilakukan dalam kehidupan sehari-hari.

Hal ini sesuai dengan pendapat Steven (2003:154) Unsur kecerdasan emosional manusia meliputi bertindak secara tanggung jawab meskipun mungkin tidakmmendapatkan keuntungan apapun secara pribadi, melakukan sesuatu untuk dan bersama orang lain, bertindak sesuai hati nurani, dan menjunjung tinggi norma yang berlaku dalam masyarakat.

Begitu pentingnya nilai kepedulian social maka sudah selayaknya program kepedulian social yang telah ada perlu ditingkatkan lagi dengan bentuk pelaksanaan lainnya. Jika membagikan santunan kepada kaum dhuafa dan anak 
yatim telah berjalan lancar ada baiknya mengadakan pengobatan gratis atau donor darah dan sunatan massal dengan menjalin kerjasama dengan puskesmas setempat. Untuk sasaran sunatan massal pun harus diprioritaskan untuk anak-anak yang kurang mampu. Hal ini dilakukan untuk meringankan masyarakat kurang mampu di saat anak laki-laki mereka menginjak umur remaja. Untuk kegiatan lainnya bisa menjalin kerjasama dengan remaja masjid setempat untuk melakukan kegiatan bakti social. Kegiatan bakti social bisa dilakukan dengan mengumpulkan pakaian bekas yang masih layak pakai kemudian dibagikan kepada mereka yang dirasa membutuhkan. Sehingga dengan bervariasinya kegiatan kepedulian social pada Jamaah Yasinan desa Sumberjo diharapkan ia tetap mampu eksis sebagai penggerak persatuan Islam.

\section{KESIMPULAN}

Dari hasil penelitian di lapangan dan dibandingkan dengan teori yang peneliti dapatkan, maka kesimpulan penelitian sebagai berikut:

1. Pelaksanaan kegiatan jamaah pengajian yasinan di desa Sumberjo telah dilaksanakan secara rutin sejak didirikan pada tahun 1974 oleh Bapak Afandi namun mengalami perkembangan yang pesat pada tahun 2000. Dengan system silaturahmi keliling atau gilir setiap hari Rabu malam Kamis seusai maghrib kemudian di akhiri dengan infaq dan arisan. Jamaah pengajian yasinan memiliki agenda-agenda kegiatannya, mulai dari agenda tahunan hingga agenda yang akan dilaksanakan. Kegiatan ini dilakukan atas dasar ukhuwah islamiyah yang mereka yakini bisa terjalini dengan erat dengan dilakukannya kegiatan keagamaan secara rutin dan terstruktur.

2. Nilai-nilai kepedulian social Jamaah Pengajian Yasinan di desa Sumberjo RT. 03 RW. 02 ditunjukkan melalui kegiatan infaq yang dilakukan setiap hari Rabu malam Kamis yang kemudian digunakan untuk menyantuni anak yatim dan kaum warga tidak mampu. Bagi ibu-ibu jamaah pengajian yasinan rasa kepedulian ini dianggap sangat pentin dalam rangka menjalankan ajaran islam dan menumbuhkan rasa kepedulian social.

\section{Daftar Pustaka}

Ahmadi, Abu.1991.Psikologi Sosial.Jakarta: Rineka Cipta.

Amin, Mansyhur. 1997.Dakwah Islam dan pesan Moral.Yogyakarta: Al Amin Press.

Arifin. 1991. Kapita Selekta Pendidikan (Islam dan Umum). Jakarta: Bumi Aksara.

Atosaki, Antonius. 2002.Relasi Dengan Semasa. Jakarta: Gramedia.

Departemen Agama RI. 2006. Al-Qur'an dan Terjemahannya Edisi Tajwid. Bandung: PT. Syaamil Cipta Media. 
Departemen Pendidikan Nasional. 2007. Kamus Besar Bahasa Indonesia Edisi ke Tiga. Jakarta: balai Pustaka.

Frenti, D., \& Huda, A. M. (2018). the Function of Indonesian Women Coalition (Kpi) in Efforts To Improve Women Leadership in Blitar City. Journal of Academic Research and Sciences (JARES), 2(2), 3. https://doi.org/10.30957/jares.v2i2.402

Huda, A. M. (2016). THE IDENTITY OF JAVANESE WOMEN (The study of Phenomenology Toward Indonesian Migrant Women Workers). Journal of Academic Research and Sciences (JARES), 1(1), 2016.

Huda, A. M., \& Martanti, D. E. (2018). Pengantar Manajemen Strategik 1. (J. Press, Ed.) (1st ed.). Bali:

http://books.jayapanguspress.org/index.php/publisher/article/view/18/18. Retrieved from

http://books.jayapanguspress.org/index.php/publisher/article/view/18/18

Istiqomah, Wiwin. 2016. Nilai-Nilai Kepedulian Sosial pada Kegiatan Jama'ah Yasinan Arroudloh di Desa Nikitan Plaosan Magetan dan Relevasinya dengan materi PAI di SMA Kelas XI.

Kustini (Ed).2007.Hasil Seminar peningkatan Peran Serta Masyarakat dalam Pendalaman Ajaran Agama melalui Majelis Taklim.Jakarta: Departemen Agama RI Badan Litbang dan Diklat Puslitbang Kehidupan Keagamaan.

Poerwodarminto, 2006.Kamus Umum Bahasa Indonesia.Jakarta: Balai Pustaka.

Romdon, 1996.Metodologi Ilmu Perbandingan gama. Jakarta: Raja Gafindo.

Sastropoetro, Santoso R.A. 1988. Partisipasi, Komunikasi, Persuasi Dan Disiplin Dalam Pembangunan Nasional. Bandung: Alumni.

Stein, Steven J. dan Howard E. 2003.Book. Ledakan EQ: 15 Prinsip Dasar Kecerdasan Emosional Meraih Sukses, terj. Trinanda Januarsari dan Yudhi Murtanto. Bandung:Kaifa.

Yunus, Mahmud. 1989. Kamus arab-Indonesia. Jakarta; PT. Hidakarya Agung. 